\title{
A CASE STUDY OF BUILDING PERFORMANCE ANALYSES USING BUILDING INFORMATION MODELING
}

\author{
Salman Azhar \\ McWhorter School of Building Science, Auburn University, Auburn, Alabama, USA \\ salman@auburn.edu \\ Justin W. Brown \\ General Assembly Architects, Birmingham, Alabama, USA \\ justin@generalassemblyarch.com \\ Anoop Sattineni \\ McWhorter School of Building Science, Auburn University, Auburn, Alabama, USA \\ sattian@auburn.edu
}

\begin{abstract}
The first decade of the twenty first century has witnessed a tremendous increase in the demand of sustainable buildings mainly due to mounting energy costs and growing environmental concerns. The most effective decisions related to the sustainable design of a building can be made in the planning and design phases. Since Building Information Modeling (BIM) allows for multi-disciplinary information to be superimposed within one model, it creates an opportunity for sustainability measures to be incorporated early in the design process. This paper presents findings of a research project to investigate the feasibility of BIM for sustainability analyses via a case study. Based on the collected data, it is found that BIM can significantly aid in performing complex building performance analyses to ensure an optimized building design. The designers can also use these results to generate necessary documentation for LEED ${ }^{\circledR}$ certification (a green building rating system used in the USA), thereby saving considerable time and resources.
\end{abstract}

KEYWORDS: Sustainability, Green building design, Building Information Modeling, Building performance analyses

\section{INTRODUCTION}

According to the World Commission on the Environment and Development, sustainable design is defined as a development meeting contemporary design and construction requirements without compromising the ability of future generations to meet their own needs (Bruntland commission, 1987). Sustainable design is based on a number of factors, primary of which are climate, culture, place, building type, and resources consumption. With the rising cost of energy and growing environmental concerns, the demand for sustainable buildings is growing day by day. Both public and private organizations are increasingly requiring architects and contractors to design and construct buildings with minimal environmental impact (Azhar and Brown, 2009).

The most valuable decisions related to the sustainable design of a building can be made in the planning and design phases. Traditional CAD-based planning environments, however, do not 
support the possibility of such early decisions (Azhar et al., 2009). Building performance analyses are typically performed after the architectural design and construction documents have been completed. This lack of continuous analysis of sustainability in the planning and design process leads to an inefficient process of retroactively modifying the design to achieve a set of performance criteria (Schueter and Thessling, 2008). In order to assess building performance in the early design and preconstruction phases realistically, access to a comprehensive set of knowledge regarding a building's form, materials, context, and technical systems are required. Since Building Information Modeling (BIM) allows for multidisciplinary information to be superimposed within one model, it creates an opportunity for sustainability measures and performance analyses to be performed throughout the design process (Autodesk, 2008; Schueter and Thessling, 2008). The term building performance analyses (or sustainability analyses), as used in this paper, refers to various assessments and evaluations (e.g. building orientation, day lighting analysis, building massing, energy analysis, etc.) typically conducted to determine a building's environmental performance.

Krygiel and Nies (2008) indicated that BIM can aid in the following aspects of sustainable design.

- Building orientation (to select the best building orientation that results in minimum energy costs)

- Building massing (to analyze building form and optimize the building envelope)

- Day lighting analysis

- Energy modeling (to reduce energy needs and analyze renewable energy options such as solar energy)

- Water harvesting (to reduce water needs in a building)

- Sustainable materials (to reduce material needs and to use recycled materials)

- Site and logistics management (to reduce waste and carbon footprints)

A recent survey of the 145 design and construction firms in the USA indicated that the practitioners implementing BIM-based sustainability analyses are realizing 'some-tosignificant' time and cost savings as compared to the traditional methods (Azhar, 2010). The combination of sustainable design strategies and BIM technology has the potential to change the traditional design practices and produce a high-performance facility design. One such effort in the Columbia campus of the University of South Carolina resulted in approximately $\$ 900,000$ savings over the next ten years at current energy costs (Gleeson, 2008).

For projects pursuing LEED ${ }^{\circledR}$ (Leadership in Energy and Environmental Design) certification (a green building rating system used in the USA), many LEED ${ }^{\circledR}$ credits require that drawings be submitted to support the qualification for credit. Although most of these drawings can be prepared using conventional CAD software, BIM software produces these drawings more efficiently as part of the building information model and have the added advantage of parametric change technology, which coordinates changes and maintains consistency at all times. Thus user does not have to intervene to update drawings or links. Similarly, such models carry a wealth of information for many other aspects of sustainable design and/or LEED $^{\circledR}$ certification process. For instance, schedules of building components can be obtained directly from the model to determine percentages of material reuse, recycling, or salvage. According to Autodesk (2005), up to 20 points for LEED ${ }^{\circledR}$ certification can be facilitated using BIM. 


\section{OBJECTIVES AND METHODOLOGY}

The study reported in this paper is part of an ongoing research project to evaluate the use of BIM for sustainable design and $\operatorname{LEED}^{(\mathrm{R})}$ certification process. Some finding of this research project can be found in Azhar and Brown (2009). This paper will specifically discuss the role of BIM for building performance analyses. The necessary data were collected via a case study of the DPR Construction Inc. headquarters building which is a 52,300 $\mathrm{ft}^{2} L E E D^{(R)}$ Gold certified facility located in Sacramento, California, USA. Figure 1 shows the front elevation of this building (left) and its resulting building information model (right).
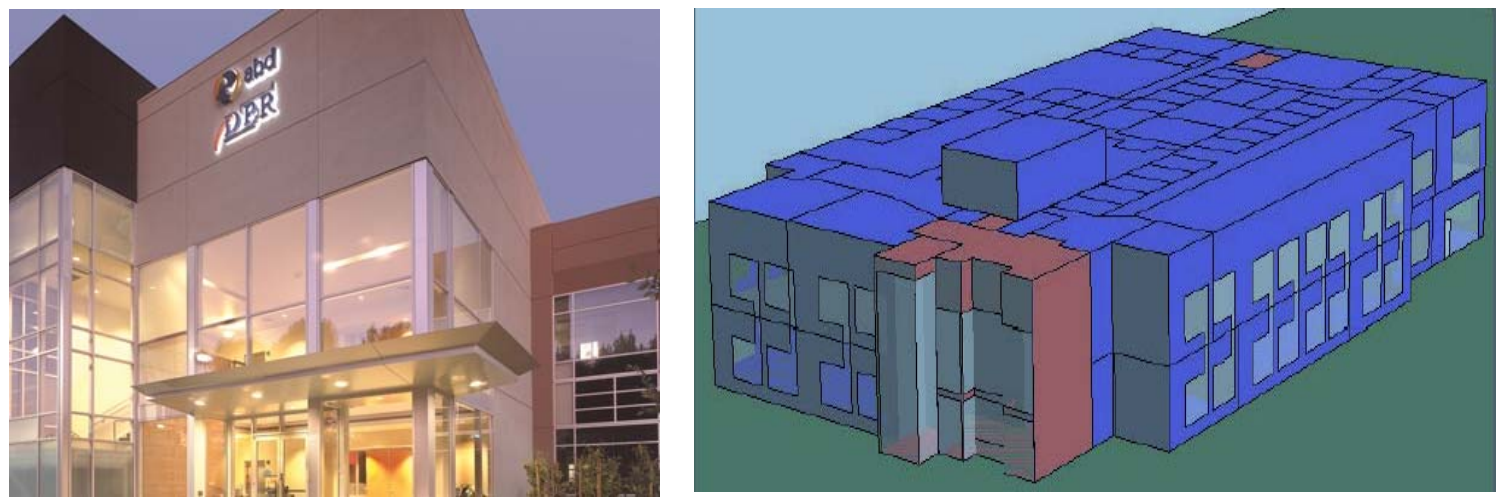

Figure 1: DPR Construction Inc. Headquarters, Sacramento, CA (Courtesy of: DPR Construction)

For this project, building performance analyses were conducted in two phases. As the building was seeking LEED $^{\circledR}$ certification and compliance with California's Energy Efficiency Standard for Residential and Non-residential Buildings, also known as Title 24, energy calculations were performed when the building was originally designed and constructed in 2002, and were finalized during the preparation of the construction drawings. These original analyses were performed by the design-build mechanical contractor, Airco, using EnergyPro ${ }^{\mathrm{TM}}$ software (a non BIM-based software). This software was chosen due to its compatibility with Title 24 . Based on the original energy code compliance calculations, the building facility was estimated to have a $20 \%$ improvement over Title 24 , which translated into a predicted $\$ 25,000 /$ year energy cost savings.

The second phase of analyses was conducted in 2008 in response to numerous clients' requests for feedback on how DPR's LEED ${ }^{\circledR}$ rated facilities are performing over time. As this was an issue in which DPR was also interested, they chose to conduct analyses to determine actual performance versus designed performance of their own headquarters building. In order to conduct these analyses, DPR created a building information model of the facility (see Figure 1) and imported it into IES Virtual Environment ${ }^{T M}\left(\mathrm{VE}^{\mathrm{TM}}\right)$ software to conduct various building performance analyses. The input and output data associated with these analyses is presented in Figure 2. Analyses performed by DPR included energy analysis, solar analysis and cost/benefit analysis. After conducting these analyses, DPR compared the results to the documented energy usage and expenditures of the building facility for the year of 2007. Researchers collected information about these analyses from the DPR construction via a questionnaire survey, telephonic interviews and e-mail exchanges. The main findings of this case study are reported in the following section while more details can be found in Brown (2009). 


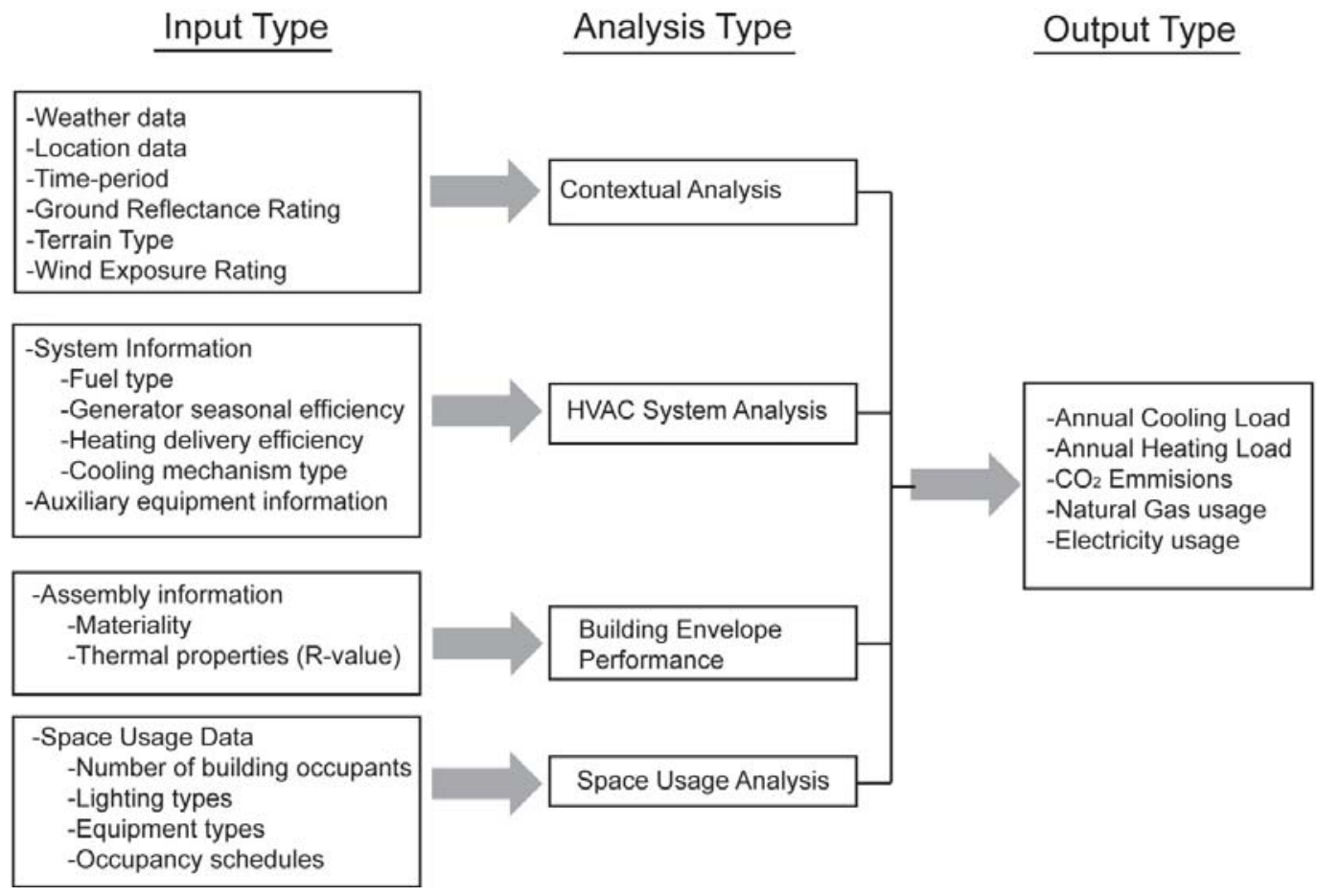

Figure 2: Input/Output Dataflow for DPR headquarters' building performance analyses

\section{DATA ANALYSIS, RESULTS AND DISCUSSION}

\section{Data Input}

\section{Building orientation and other contextual data}

To conduct the building performance analyses, DPR incorporated multiple types of contextual information into the IES Virtual Environment ${ }^{\mathrm{TM}}$ (IES-VE $^{\mathrm{TM}}$ ) software. To simulate the effects of the buildings orientation within its immediate context, as well as its overall geographic location, information related to its site location was entered in the software. Site related data input also included weather data for a typical year. This information is entered through an integrated IES-VE ${ }^{\mathrm{TM}}$ interface known as Location and Weather Data Wizard. Through the use of this wizard, location data including city and state, latitude, longitude, altitude, and time zone was extrapolated and associated with the simulation. DPR was also able to affect the performance analyses by defining the time period, in months, in which the simulation was to take place. In addition to this information, DPR defined detailed site information relating to the impacts of the immediate site. This included a ground reflectance rating, terrain type, as well as a wind exposure rating. For an example of this interface, see Figure 3 (DPR Construction Inc., 2008). 


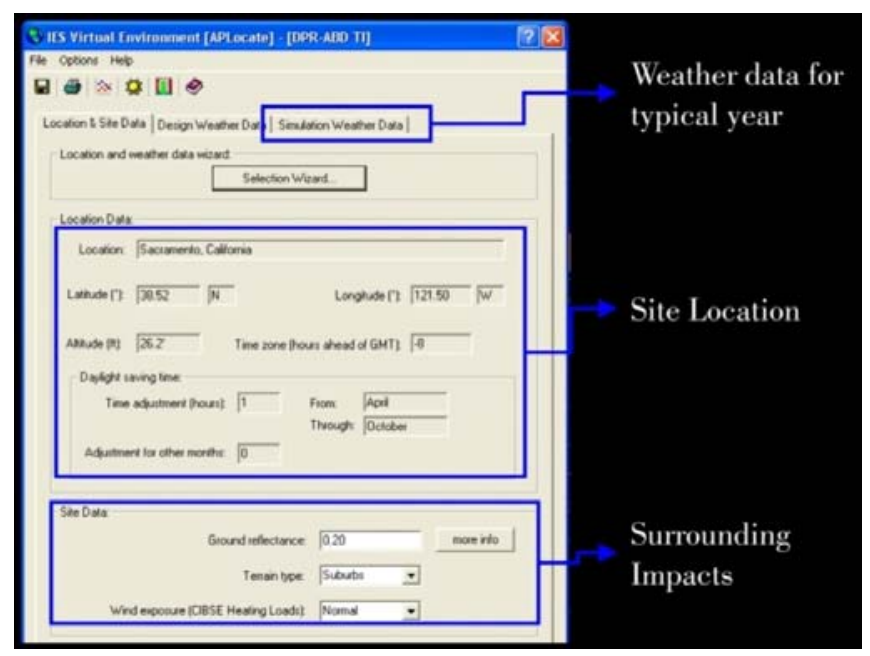

Figure 3: IES Virtual Environment ${ }^{\mathrm{TM}}$ - Site Location Data Interface (Courtesy of: DPR Construction)

\section{HVAC system}

Input data related to the type of HVAC system was also entered into the IES-VE ${ }^{\mathrm{TM}}$ system. This process is supported through an interface which allows a user to define the type of HVAC system. After selecting a system type, information is entered which defines the facility's heating system type and properties. Among the types of information available for selection or input include fuel type (such as natural gas), generator seasonal efficiency, and heating delivery efficiency. Cooling system information which is entered includes cooling mechanism type such as air conditioning, generator type, heat rejection pump and fan power, as well as cooling delivery efficiency. Additionally, the user is able to include information pertaining to auxiliary equipment such as fans, pumps, and controls. An example of this interface is shown in Figure 4 (DPR Construction Inc., 2008).

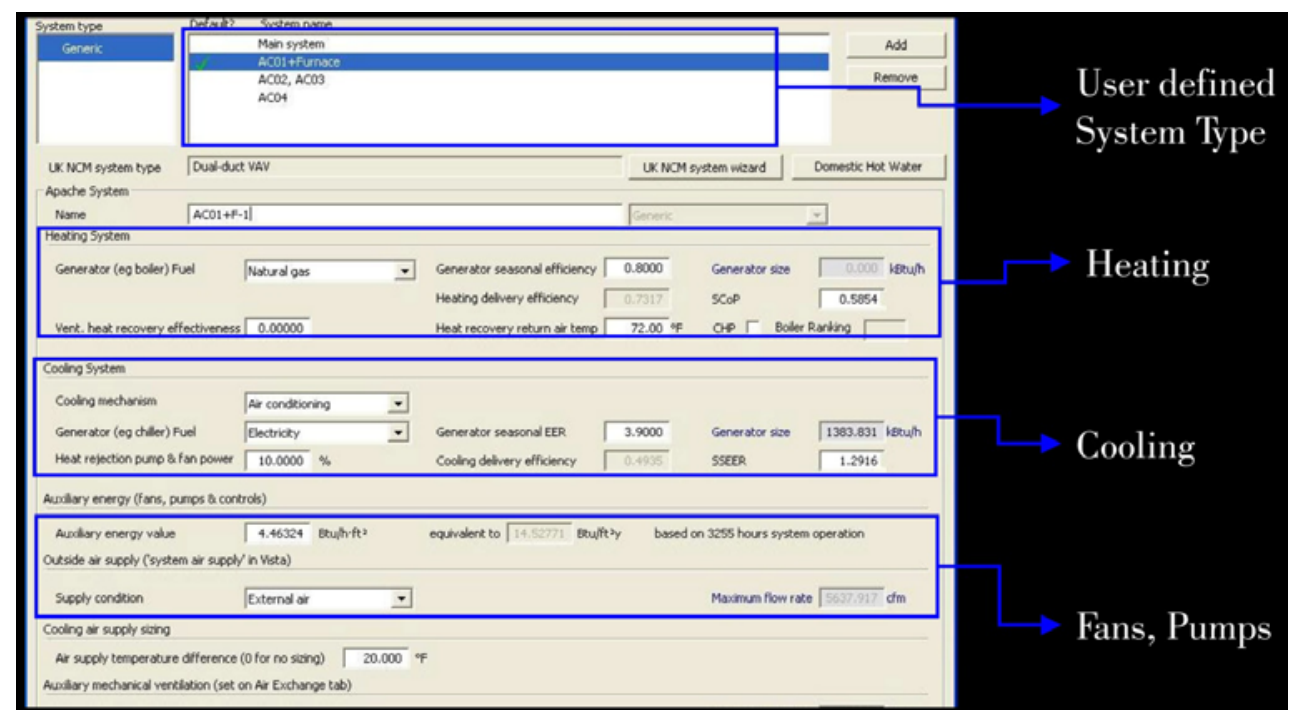

Figure 4: IES Virtual Environment ${ }^{\mathrm{TM}}$ - HVAC Data Interface (Courtesy of: DPR Construction) 


\section{Building envelope and space usage}

Also contributing to the energy usage assessment was data which defined the materials used for the building envelope, as well as space usage data. The building envelope information was defined, based on architectural drawings and specifications, as an assembly. This assembly's material properties, such as R-value and material mass, were then evaluated by the IES-VE ${ }^{\mathrm{TM}}$ to determine the effect of the envelope on building energy performance. Space usage data was also entered which defined the quantity of people expected to use the space, lighting types, and equipment types. These factors were combined to determine internal gains to the cooling load as shown in Figure 5. These internal gains were supplemented by occupancy schedules which evaluated the facility based on an estimated daily and weekly usage (DPR Construction Inc., 2008).

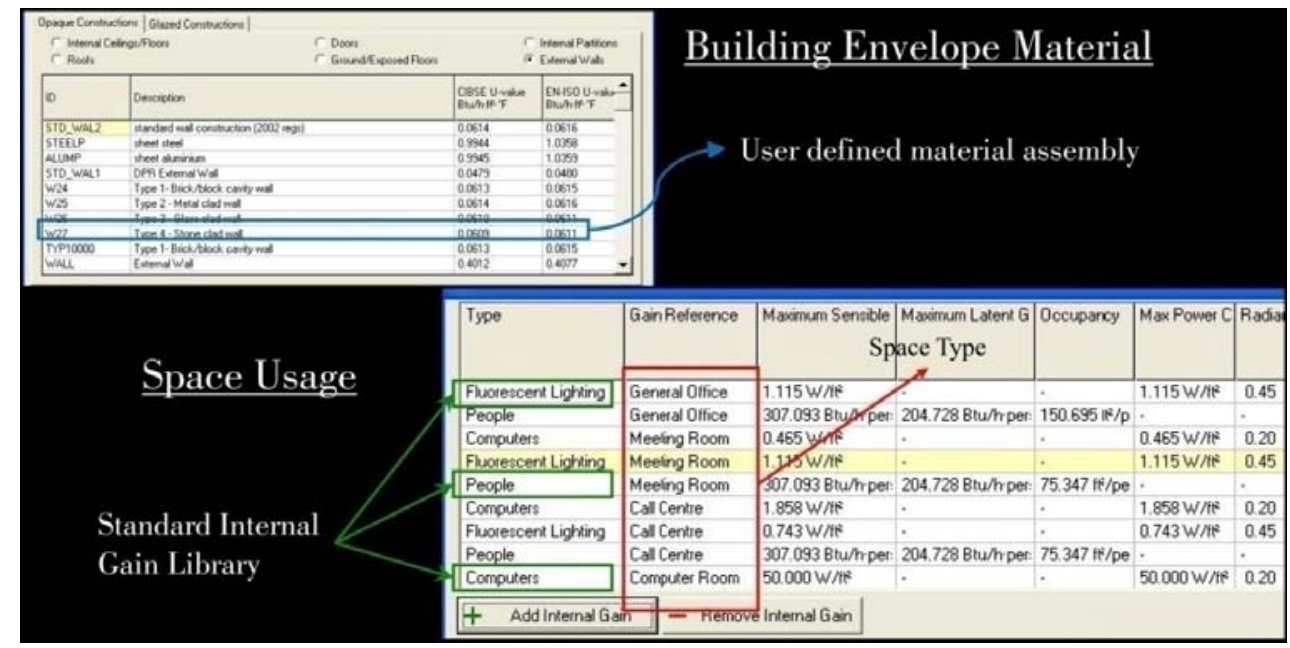

Figure 5: IES-VE ${ }^{\mathrm{TM}}$ - Envelope and Space Data Interfaces (Courtesy of: DPR Construction)

\section{Building Performance Analyses Results}

\section{Energy analysis}

By methodically defining the facility through the set of criteria presented in this study, IES Virtual Environment ${ }^{\mathrm{TM}}$ was able to determine the energy performance of the building. This performance analysis resulted in a graph illustrating the heating and cooling load quantities as the building would experience throughout a typical year. Also provided were the yearly heating and cooling system $\mathrm{CO}_{2}$ emissions, categorized by month. These results are illustrated in Figure 6 (DPR Construction Inc., 2008). 


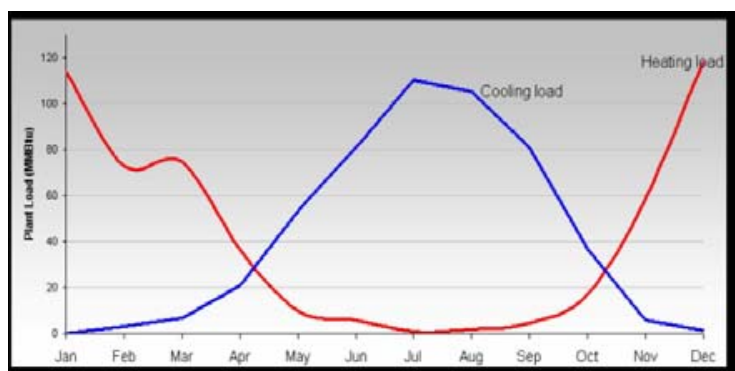

Heating and Cooling Loads

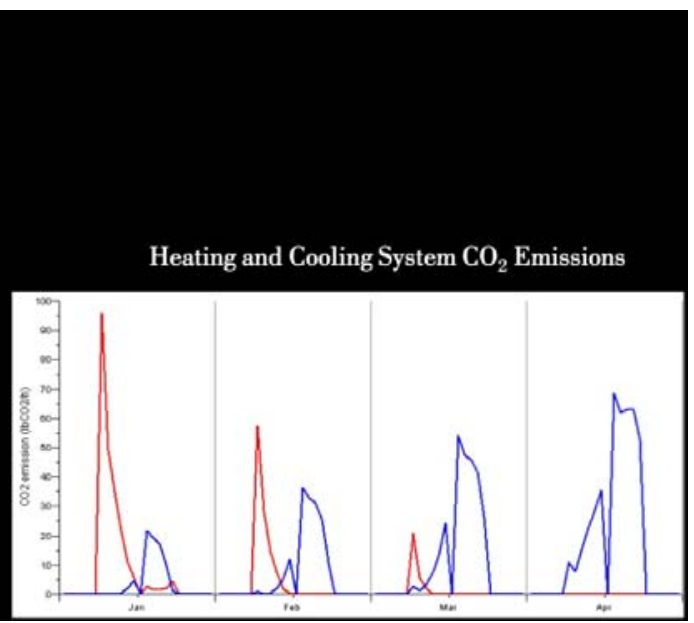

Figure 6: IES-VE ${ }^{\mathrm{TM}}$ - Envelope and Space Data Interfaces (Courtesy of: DPR Construction)

Other results which were produced include the facility's natural gas usage and electricity usage. These results were compared to the actual results as documented post-occupancy by DPR. The model value versus actual value comparisons are shown in Figures 7 and 8 (DPR Construction Inc., 2008).

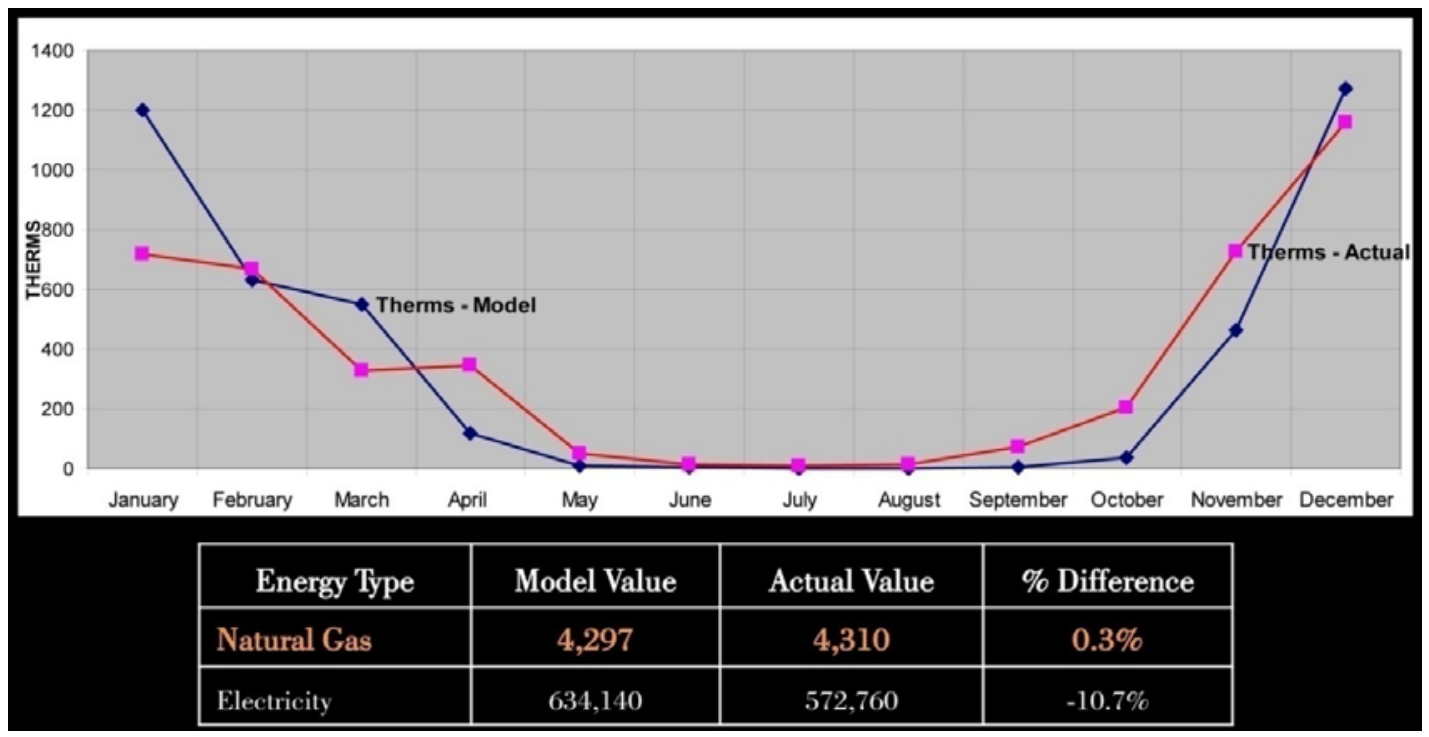

Figure 7: Results - Energy Usage by Fuel - Natural Gas (Courtesy of: DPR Construction) 


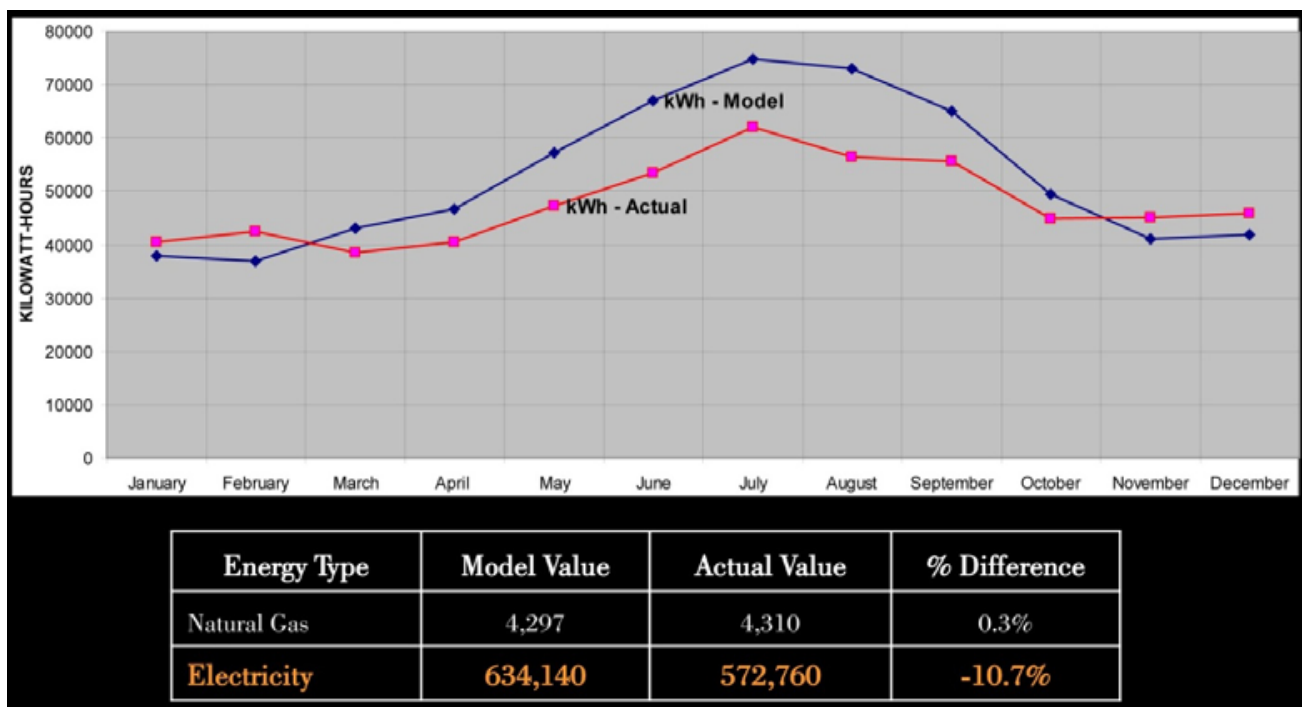

Figure 8: Results - Energy Usage by Fuel - Electricity (Courtesy of: DPR Construction)

\section{Solar shading device analysis}

In addition to the energy analysis, a separate analysis was performed with the intent of evaluating the amount of building area which would experience direct solar incidence. This analysis was performed both with and without the shading devices. As shown in Figure 9, without the sun shading devices, the percent area of direct solar incidence would total $67.12 \%$ of the total surface area of the building. When the sun shading devices were introduced into the model, the percent area of direct solar incidence was reduced to $48.17 \%$, providing a $19 \%$ reduction in building facility surface area experiencing direct solar incidence which could further help to reduce the energy costs.

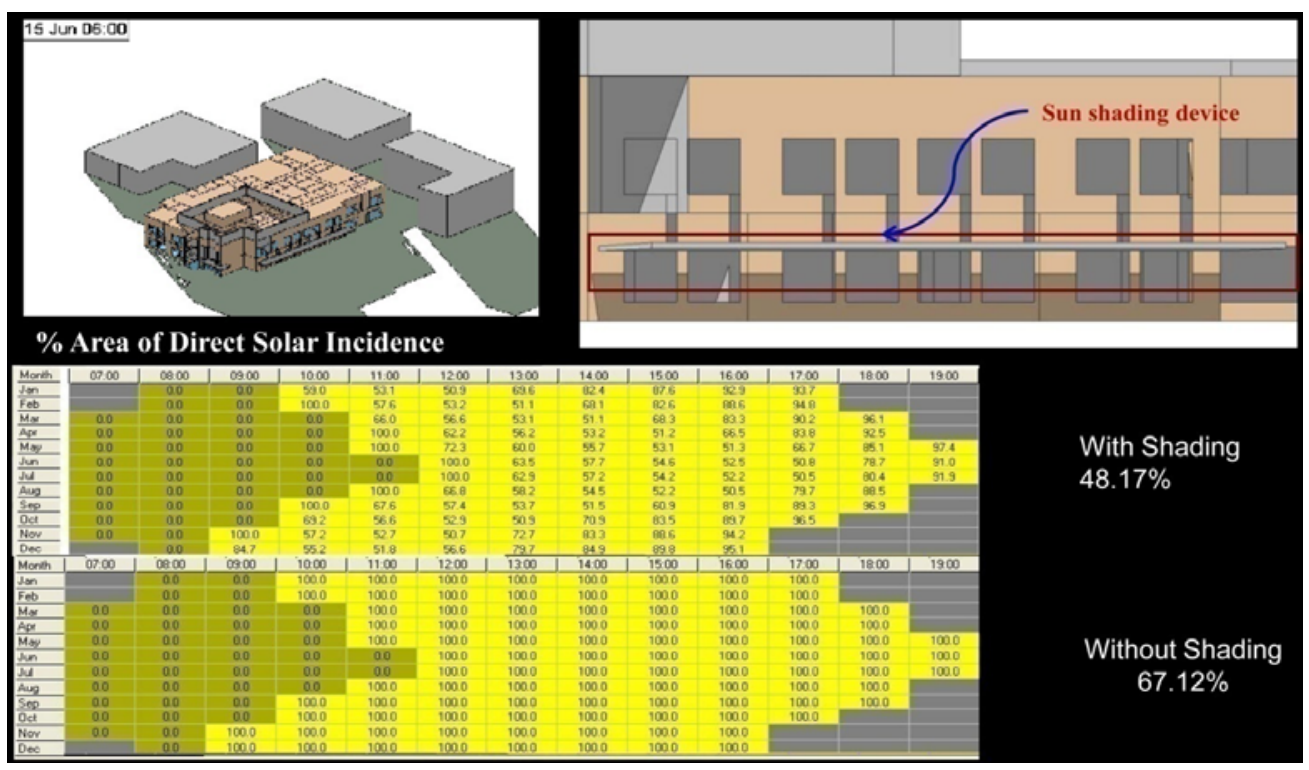

Figure 9: Results - Energy Usage by Fuel - Electricity (Courtesy of: DPR Construction) 


\section{Benefits of BIM-based Building Performance Analyses}

In regard to cost savings realized through the building performance analyses, DPR realizes approximately \$28,000/year in energy savings or 27 percent less than BOMA (Building Owners and Managers Association) industry average for office buildings in the building's geographic region. This is an improvement on the original design, which estimated a 20 percent improvement over the California standard energy code or Title 24. As previously mentioned, the 20 percent improvement would have resulted in an energy costs savings of approximately $\$ 25,000 /$ year. One of the motivating factors in conducting the energy analysis was for DPR to determine how their projects are performing. These results clearly indicate that their building is performing within 10 percent of the actual energy usage. Therefore, the results confirm that the building is performing in accord with the original design intent as well as the simulations. It can therefore be concluded that their current BIM-based building performance analyses methods are, in fact, accurate and effective. DPR was not able to quantify an amount of time savings as they did not have documentation for any type of comparative analysis.

\section{Future Risks and Challenges}

In regard to foreseen future challenges, DPR stated that the most significant challenges faced by the company are:

1. Lack of interoperability between various BIM-based applications.

2. Mechanical design community slow to embrace BIM-based energy analysis applications. This is because a non-BIM based analysis software is currently approved and used for sustainability related analyses (known as DOE- $2^{\mathrm{TM}}$ ).

3. No BIM-based energy analysis applications certified by the California Energy Commission (CEC). DPR believes that if the CEC approved IES-VE ${ }^{\mathrm{TM}}$ for Title 24 compliance, more mechanical engineers would be open to adopting BIM-based sustainability analysis.

\section{CONCLUSIONS}

The main findings of this study are as follows:

- Client requests for information regarding the performance over time of DPR Construction's LEED ${ }^{\circledR}$ certified facilities were the primary factor leading to DPR's comparative analysis.

- DPR realizes $\$ 28,000 /$ year in energy savings. Although this savings is a result of nonBIM based energy analysis, DPR's comparative analysis concluded that the BIMbased evaluation methods they currently use perform as well, if not better, than this result.

- DPR's current method of energy analysis, which is BIM-based, saves the company, as well as other project stakeholders both time and money.

- Risks and challenges of BIM-based building performance analyses include lack of interoperability between various BIM-based applications, the relative slowness of the mechanical design community in adopting BIM, and a lack of BIM-based analyses applications certified by the California Energy Commission. 


\section{ACKNOWLEDGMENTS}

The authors would like to thank Nils Blomquist and Todd Armistead of DPR Construction Inc. for providing necessary data and feedback. The study is supported by the seed grant provided by the College of Architecture, Design and Construction at Auburn University.

\section{DISCLAIMER}

The opinions expressed in this paper are the authors' personal opinions and do not necessarily represent the official position of any organization.

\section{REFERENCES}

Autodesk, Inc (2005) Building information modeling for sustainable design. Available at http://www.federalnewsradio.com/pdfs/BuildingInformationModelingfor

SubstainableDesign-white\%20paper.pdf.

Autodesk, Inc (2008) Improving building industry results through integrated project delivery and building information modeling Available at http://images.autodesk.com/adsk/files/bim_and_ipd_whitepaper.pdf.

Azhar, S (2010) BIM for sustainable design: results of an industry survey. Journal of Building Information Modeling, 2(1).

Azhar, S. and Brown, J (2009) BIM for sustainability analyses. International Journal of Construction Education and Research, 5(4), 276-292.

Azhar, S., Brown, J. \& Farooqui, R (2009). BIM-based sustainability analysis: an evaluation of building performance analysis software. Proceedings of the 45th ASC Annual Conference, Gainesville, Florida, April 1-4, 2009.

Brown, J (2009) Benefits of building information modeling based sustainability analysis, MBC thesis, Auburn University, Auburn, Alabama.

Bruntland Commission (1987) Our Common Future, United Nations General Assembly Document A/42/427.

DPR Construction Inc (2008) Building great green things. Ecobuild Fall, Washington D.C.

Gleeson, J (2008) Computer-aided green design. Available at http://www.architectureweek.com/0330/tools_1-2.html.

Kriegel, E. \& Nies, B (2008) Green BIM. Indianapolis: Wiley Publishing, IN.

Schueter, A. \& Thessling, F (2008) Building information model based energy/exergy performance assessment in early design stages. Automation in Construction, 18 (2), 153-163. 